\title{
Issues Surrounding Academic Achievement in Japan: Examining the 2008 Revisions of the National Courses of Study
}

\author{
NISHIOKA, Kanae*
}

This paper will shed some light on the current state of discussion of academic achievement in Japan and the issues associated with it. It will summarize the controversy regarding the significance of reading, writing, and arithmetic (3Rs); the relationship between mastery and inquiry; and the importance assigned to desire and attitude, while at the same time examining the image of academic achievement in the March 2008 reform of the National Courses of Study (NCS).

Two camps have emerged regarding the 3Rs: the first sees the $3 R s$ as simple tools, while the second believes in establishing a conceptual understanding of the 3Rs as a foundation. The 2008 Revision of the NCS was influenced by both camps; however, effectively fostering literacy will require an approach that emphasizes the ideas of the latter.

The controversy over the relationship between mastery and inquiry centers on the Period for Integrated Study (PFIS). The 2008 Revision of the NCS calls for the mastery and application of knowledge in subject classes, with inquiry during the PFIS. It calls for the development and use of performance tasks in the curriculum, with a view to achieving this framework.

There are two conflicting views of desire and attitude: one claims that these support cognitive development, and the other claims that these develop along with cognitive development. The 2008 Revision of the NCS favors the former view, and threatens to pass on the responsibility for failure in academic achievement to children and their families. It is probably more appropriate to view desire and attitude as long-term goals that are nurtured through the overall curriculum.

In order to realize these visions, it will be meaningful to learn the theory of Understanding by Design, advocated by Grant Wiggins and Jay McTighe.

\section{Foreword}

In March 2008, a new National Course of Study (NCS) was released in Japan. Implementation of this NCS will begin in 2009 and will be completed in 2011. The 2008 NCS preserves the

\footnotetext{
*Kyoto University

e-mail: nishioka@educ.kyoto-u.ac.jp
} 
concept of fostering the "zest for living" originally advocated by the 1998 NCS, which is currently still in effect. However, the 2008 version has been called the biggest revision in 30 years, as it marks a major policy shift from the Relaxed Education policy (Yutori Kyoiku) to a Policy for Improving Academic Achievement (Gakuryoku Koujou). In this paper, I examine the nature of the academic achievement (gakuryoku) sought by the 2008 NCS.

In fact, the English translation of "gakuryoku" as it relates to Japan, is somewhat problematic in itself. The Ministry of Education, Culture, Sports, Science and Technology (MEXT) offers "academic ability" and "learning ability" as translations. However the word "gakuryoku" is not commonly used to refer to learning abilities in general with regard to pedagogy in Japan. Rather, by convention "gakuryoku" is only used to refer to knowledge, skills, and so on that students acquire as a result of a teacher's conscious effort to have them attain educational goals. Thus in this document, "gakuryoku" has been translated as "academic achievement."

The image of academic achievement in the 2008 NCS is described in the following statement found in a report issued on 17 January 2008 by the Central Council for Education (CCE), entitled "National Courses of Study Reform for Kindergarten, Elementary Schools, Lower and Upper Secondary Schools, and Special-Needs Schools," which this document will refer to hereafter as a "The 17 January 2008 Report."

"The vital elements of academic achievement are as follows:

1. The mastery of basic and fundamental knowledge and skills

2. Ability to think, judge and express what is necessary to solve problems applying acquired knowledge and skills

3. The desire to learn." (CCE, 2008, p.10)

This paper clarifies the meaning of the council's answers by examining the controversy leading up to the proposal of this image of academic achievement, and also considers the current state of, and issues involved in, the controversy over academic achievement in Japan. In this paper, the discussion focuses on the following three points.

The first is how we look at the 3Rs. There are two viewpoints here; one in which the $3 \mathrm{Rs}$ are seen as simple tools that must be learnt, and another which views them as a foundation for general understanding. The 17 January 2008 Report was influenced by both of these views.

The second point is how we perceive the link between mastery and inquiry. This is related to the status we give the Period for Integrated Study (PFIS). The 17 January 2008 Report emphasizes the mastery and application of knowledge for the subject classes, and inquiry in the PFIS.

The third point relates to how we value desire for and attitude toward learning. There are two conflicting views of desire and attitude: one claims that these support cognitive development, and the other claims that these develop along with cognitive development. The 17 January 2008 Report can be seen as stressing the former.

The following paper attempts to provide a theoretical summary of these points and to investigate effective ways to improve the curriculum.

\section{View on the Significance of the 3Rs}

The first point is how we view the basic academic achievement of the 3Rs. In Japan, views 
on this issue can be broadly divided into three groups. The first group embraces a drill-centric philosophy (drill-shugi) that emphasizes simple repetitive training in the $3 \mathrm{Rs}$. The second group embraces empiricism (keikenshugi) that emphasizes the attitude with which one approaches study. This group tends to regard the 3 Rs as simply a tool. The third group embraces systemism (keitoshu$g i$ ), and views the 3 Rs as a basis for scholarship and culture.

It may be useful to briefly recount the history behind the shift in government policy from Relaxed Education to that of Improving Academic Achievement. The Relaxed Education policy was a response to the "drop-out" problem that appeared in the 1970s. The first NCS, created right after the war in 1947, and the 1951 version were influenced by empiricism that emanated strongly from the United States. Education at this time was referred to as post-war New Education. However, the 1958 and 1968 reforms took a sudden turn towards emphasizing systemism in courses, and the content became more challenging. From 1955 to 1973, Japan underwent a period of high economic growth. Throughout this period interest in education became more pronounced, giving rise to two problems in the 1970s: the intense pressure of entrance exams and school drop-outs. Against this backdrop, people began to wonder if the NCS might be excessively demanding. The 1977 NCS stated, "we should avoid ...... placing an excessive burden on our children" (MESC, 1977, p.1) and introduced "Relaxed Periods (Yutori no Jikan)."

Rather than subsiding, educational problems multiplied in the 1980s and 1990s, with bullying, truancy, and the breakdown of discipline in the classroom. With the industrial structure changing in the face of internationalization and computerization, it seemed that the "ability to proactively deal with changes in society" (MESC, 1989, p.1) was becoming more important than mere volume of knowledge. The 1989 NCS touted an education that nurtures "the desire to learn on one's own," and the science and social studies curriculums were replaced by life environmental studies for first- and second-grade elementary school students. The 1991 Cumulative Guidance Records placed most importance on "interest, desire, and attitude," and emphasized these as the focus for "new academic achievement (Atarashii Gakuryoku)." The 1998 NCS promoted education that taught children to learn and to think for themselves, and introduced the Period for Integrated Study (PFIS) to the education system from elementary school to high school. Both Life Environmental Studies and PFIS placed more emphasis on inquiry by the children themselves than on the acquisition of knowledge.

With the introduction of the Relaxed Education policy, pedagogical academic circles in the 1990 s questioned and criticized the very notion of "academic achievement," and there were calls for a shift from "academic achievement" to "learning." By way of example, Manabu Sato (1992) wrote, "the value of education should be sought neither in the content of the materials that are prepared beforehand nor in academic achievement that is measured by the results of learning, but rather in the learning experience itself" (p.215).

However, in March 1999, the weekly magazine Shukan Asahi ran a sensational article describing how the academic achievement of students at some of Japan's top universities (including the University of Tokyo and Kyoto University) was "collapsing." In June of that same year, a group of mathematicians and economists published a book entitled University Students Who Can't Do Fractions (Okabe, Tose \& Nishimura, 1999), highlighting the decline in academic ability among university students. The authors were the first to report that students were given broad freedom to select topics for their entrance exam, and that some students were thus admitted to university despite not possessing the basic academic skills necessary for a university education. This criticism led to broader criticism of the Relaxed Education policy that was being promulgated in primary 
and secondary education. Sociologist of education, Takehiko Kariya $(1999,2002)$ described the downward trend in the number of hours that upper-secondary-school students spent studying, and showed that the strength or weakness of this trend correlated to the occupation or educational background (i.e. the social class) of the parents. Thus he argued that the Relaxed Education policy would increase the gap in academic achievement between the social classes.

As the feeling of crisis permeated the trenches of education, the drill-centric view gathered momentum. The most famous proponent of this view at that time was Hideo Kageyama. Kageyama's influence was responsible for re-popularizing reading aloud, listening/viewing and writing, and the use of a special mathematics training regime called 100-Box Calculations. This technique uses an 11-by-11 grid with the digits 0 to 9 written across the top row and down the left-hand column in random order. Students then perform calculations on two numbers, one from the left-hand column and one from the top row, and write the result at the point where the row and column intersect (Kageyama, 2002). It was created by a teacher, Hiroshi Kishimoto in the 1970s at the peak of the "drop-out" problem (Kishimoto, 1981). Kishimoto and Kageyama emphasized "routine expertise," in which students practice the 3 Rs repetitively until they can do them quickly and accurately (Matsushita, 1994, 2004).

Confronted with these theories about the decline in academic achievement, empiricism suggested that the academic achievement that really needed be taught in contemporary schools were ability of application and the desire to learn, rather than superficial academic knowledge that could be measured using a written exam (Kato \& Takaura, 2001). These arguments bear a striking resemblance to the counter arguments with which Seishiro Aoki (1949) responded to detractors of the post-war New Education policy. Empiricism, in some cases, views the 3Rs as mere tools, which is actually similar to the drill-centric view.

In January 2002, Minister of Education, Culture, Sports, Science and Technology Atsuko Toyama released an urgent appeal for "promoting learning," which marked a turning point in education policy and an emphasis on improving "comprehensive learning ability" (the MEXT's translation of Tashikana Gakuryoku; the literal translation is "definite academic achievement"). The 1998 NCS was partially revised in 2003, and it was argued that NCS clarifies the minimum essentials and that additional content could be taught.

However, policies that sought to improve academic achievement were to enter a new era in December 2004. At this time, the PISA2003 survey results were released, and everyone learned that reading literacy among Japanese students had dropped to the OECD average. The "PISA shock" spread, and in December 2005 the MEXT formulated the Reading Literacy Improvement Program and published the Instructional Guidelines for Improving Reading Literacy. Reading literacy as used in the PISA survey is defined as "understanding, using and reflecting on written texts, in order to achieve one's goals, to develop one's knowledge and potential, and to participate in society" (OECD, 2003, p.108). With this, it was clear that efforts to improve PISA-style "reading literacy" differed markedly from the practical efforts being made to improve the simple 3Rs.

Among Japanese pedagogues, advocates emerged (systemists) for a view of the importance of the 3Rs that differed from that offered by drill-centric philosophies and empiricism. In the 1950s, Ichitaro Kokubun (1954) said that the 3Rs were the "key" to the "treasure chest of human civilization" (p.61). Fumio Shiromaru (1959) argued that the 3Rs are "recognition in and of themselves" (p.90) and that contained therein is "an awareness of reality from which the abstract and conceptual may be formed" (p.96). Advancing this line of thought further, Yoshimatsu Shibata (2003) argued exhaustively on the virtues of the 3Rs. Referencing the research of Pavlov, Vygotsky, and 
Piaget, Shibata argued that development of the written word is deeply connected with "higher-order mental activities," such as logical memory and reflective thinking, and the development of a system of concepts (pp.59-60, p.62). In addition, he indicated that the concept of numbers is "the first system of scientific concepts that a child encounters at school" (p.65).

The 17 January 2008 report declared that there would be "an emphasis on the nurturing of ability in the 3Rs through repetitive practice and thinking, and on understanding using physical objects and experiential knowledge" (CCE, 2008, pp.23-24). This could be said to be a combination of the thinking of drill-centric philosophy, empiricism, and systemism. To make it possible to nurture a literacy that allows one to "achieve one's goals, to develop one's knowledge and potential, and to participate in society," it would seem to be necessary to introduce the 3 Rs as something that can join conceptual understanding and methods of recognition, rather than just through simple repetitive practice.

\section{View on the Relationship between Mastery and Inquiry}

The second point of controversy over academic achievement in the 2008 NCS is how one regards the relationship between the mastery of knowledge and skills, and children's inquiry.

Most symbolic of the special characteristics of the 1998 NCS was the introduction of the Period for Integrated Study (PFIS). The general rules of the PFIS include the following. Item 2 (3) was added during the partial revision of 2003.

"1. During the PFIS, each school will engage in educational activities that show ingenuity in the use of cross-disciplinary and integrated learning appropriate to the region, school, and condition of the children, and learning based on the interests and concerns of the children.

2. During the PFIS, instructional activities will be conducted with the following purposes.

(1) To foster in children the character and ability to discover problems by themselves, to learn, think, and actively decide on their own, and effectively solve these problems.

(2) To enable children to find their own ways of learning and thinking, and foster an attitude of pro-active and creative effort in problem solving and inquiry, so that they can consider for themselves how they would like to live.

(3) To interrelate the knowledge and skills acquired through individual subjects, ethics classes, and special activities, so that the children can apply them in learning and life, and function effectively in all areas." (MEXT, 2003, pp.2-3)

We now understand that the 1998 NCS emphasized the ingenuity of individual schools.

The importance that the PFIS had within the curriculum became a point of controversy when it was introduced. The empiricists claimed that the overall viewpoint and method of integrated study permeated all educational courses. For example, Sato (1999) argued that "the essence of curriculum reform is the replacement of the units of the 'objectives, accomplishment, and assessment' model, which has sought productivity and efficiency, with the units of the 'theme, inquiry, and expression' model, which represents learning as a significant experience" (p.111). The units of the "objective, accomplishment, and evaluation" model are units in which the teacher sets 
the objectives, teaches according to them, and assesses whether children achieve the objectives; whereas the units of the "theme, inquiry, and expression" model are units in which the teacher only gives the theme to be inquired, and children conduct inquiry and express their findings.

In contrast, the systemists advanced the claim that integrated study could be seen as just another form, or as an advanced form, of subject classes. For example, Jun Koyasu (1999) thought that even if in PFIS one takes up modern issues that are not currently taught in subject classes, "it is essential to establish a new subject for such interdisciplinary content if necessary" (pp.53-55).

As a third option, another argument appeared that saw integrated study as the "scope" of the curriculum, that forms a positive feedback loop with subject classes. Examining the practice at Wako Elementary School, a famous school for its integrated study, Koji Tanaka (1999) said, "the subject classes involve systematic learning activities in which the children work towards educational goals set by the teachers, while integrated studies involve student inquiry together with teachers into general problems faced by the children in their daily lives. Through this process they primarily learn methodology" (p.17).

Once the mass media began to report on the decline in academic achievement, the PFIS also came under fire. The criticisms of integrated studies by those decrying the decline in academic achievement can be roughly summarized by the following three points (Ohno \& Ueno, 2001; Wada, 2002; Kariya, 2002). First, even if the value of pro-active inquiry by children is acknowledged, without a broad foundation of knowledge and skills, inquiry is not possible. If integrated studies are introduced to the point of eroding the subject-based education that gives children that type of knowledge and skills, their knowledge and skills will tend to be unbalanced. Second, historically in foreign countries, integrated studies have been successful only at schools blessed with ideal conditions - namely a full complement of teaching staff, high academic achievement among children, and high awareness among parents and guardians. Educational methods that were possible under those conditions cannot be introduced into ordinary schools without adequate financial and human resources. Third, if integrated studies are still introduced, underprivileged children will be further disadvantaged, and the gaps between social classes will widen.

Against the backdrop of these criticisms, everyone was waiting to see if the PFIS would survive the next round of NCS reforms. However, the 2008 NCS reforms choose to continue the PFIS. A new chapter was established for the PFIS, and its goals were clearly stated as follows.

\section{"Article 1 Goals}

Use cross-disciplinary and integrated learning, and learning through inquiry to nurture the natural talent and ability to discover problems on one's own, and learn, think, and proactively decide on one's own to achieve a better resolution to problems, and acquire the methods of thinking and learning that will foster an attitude of pro-active, creative, and cooperative effort towards problem solving and inquiry, so that children can decide for themselves how they wish to live." (MEXT, 2008, p.98)

In addition, each school was given the authority to set specific objectives and the content of the class.

The relationship between subjects and the PFIS was stated in the 17 January 2008 report.

"Essentially, subjects are learning activities where basic and fundamental knowledge and skills are acquired, observations and experiments are performed, and reports are written 
about the results. In addition, books and papers are read, with children organizing their thoughts in view of their knowledge and experience to write an essay. The purpose of the PFIS is to further develop this experience into problem-solving learning and inquiry that spans all subjects. These learning activities are interdependent and cannot be clearly classified; however, learning activities in which knowledge and skills are applied, and inquiry is made based upon the results of theses activities, foster the ability to think, judge, and express." (CCE, 2008, p.18)

Thus the report posits a division of labor in which the subjects aim for the mastery and application of knowledge and skills, while the PFIS engages in inquiry. It should be noted that a student's ability to apply knowledge and skills - an ability ranked second on the list of three academic achievements - is seen as a method of enriching PFIS.

However, there are three possible concerns about making the application of knowledge and skills an academic achievement. First is the danger that application will remain at a low level. Spurred into action by criticism of declining academic achievement, MEXT introduced the National Academic Achievement and Learning Status Survey. The survey is divided into sections A and B. Section A assesses knowledge and skills learned, while section B assesses the ability to "apply" them. However, Section B is a written test, and it is difficult to assess the application of knowledge or skills in a real context. If the ability to apply knowledge and skills is as represented by Section B, it leaves room for doubt about whether or not the students are acquiring the "ability to think, judge, and express" themselves so as to lead to inquiry during the PFIS.

The second concern is the danger of ending up as activities that have nothing to do with knowledge and skills. Learning activities such as the creation of reports have been emphasized in the image of the "new academic achievement." However, these reports tended to be simply the regurgitation of information and in many cases did not result in deep understanding. As touted in the 17 January 2008 report, to nurture the "ability to think, judge, and express" oneself, it is necessary to clarify which knowledge and skills must be applied. However, the 2008 NCS does not annunciate this point clearly.

The third issue is the risk in dividing children into those who work to "master" knowledge and skills and those who work at "applying" them. The revisions made to the National Courses of Study in 2008 promote instruction tailored to the individual. However, depending on their level of proficiency, carrying out instruction at a low level may deprive children of the opportunity to learn "application."

A thought-provoking theory for overcoming these concerns is Understanding by Design (which is also called "backward design") advocated by Wiggins and McTighe (1998, 2005; See also Nishioka, 2005, and Tanaka, 2008a). They identified three levels of importance in the "structure of knowledge": factual knowledge and discrete skills, which are worth being familiar with; transferable concepts that are important to know and complex processes that are important to do, and "enduring understanding" regarding principles and generalizations (McTighe \& Wiggins, 2004, p.65). They also advocate making a goal of "essential questions" that makes it possible to uncover "enduring understanding." Further, they advise us to use performance tasks in order to assess whether children have acquired "enduring understanding" and are able to pose "essential questions" on their own.

Performance tasks are those that require the synthesis and mastery of both knowledge and skills in a real context (or alternatively, in a simulated context). The resulting products (e.g. reports 
and pictures) or performances (e.g. speeches and experimental processes) are assessed. Teachers create a rubric by analyzing students' work (products and/or performances), and improve their teaching methods, taking into consideration students' actual attainments and failures.

I have been involved in joint research with Japanese teachers to develop performance tasks based on the theories of Wiggins and McTighe (Nishioka, 2007, 2008). During the course of this research I have come to realize the significance of the curriculum design theory, as follows. First, the requirement for performance tasks means that students must be able to apply their knowledge and skills at a high level. Moreover, when planning instruction, stipulating what "enduring understanding" students are to acquire allows the teacher to clearly define goals for how knowledge and skills are to be applied. The teachers with whom I am conducting this research give performance tasks to all students, regardless of their level of ability. At the same time, working to improve instruction has been effective for students of all abilities.

\section{Importance Assigned to Desire and Attitude}

The third point is the importance that desire and attitude are given in academic achievement. Discussion of this point involves a number of affective factors such as sense of values, ability to empathize, motivation, and learning habits. This is considered to be a point that touches broadly on the relationship between academic achievement and personality.

Ryozo Hirooka had previously confronted this point. Hirooka (1953) tried to merge the lively, progressive academic achievement emphasized by the empiricists with the scientific academic achievement emphasized by the systemists (p.190). Figure 1 shows the academic achievement model (structure) proposed by Hirooka (1964). This figure includes knowledge/skills and attitude. This academic achievement model resonated with many teachers and was widely supported. However, critics of the idea of placing knowledge and skills on a par with attitude said that this undervalues the power of science and art to form personalities, and that if attitude is given precedence, it will not be possible to preserve systematic knowledge and skills, and the responsi-

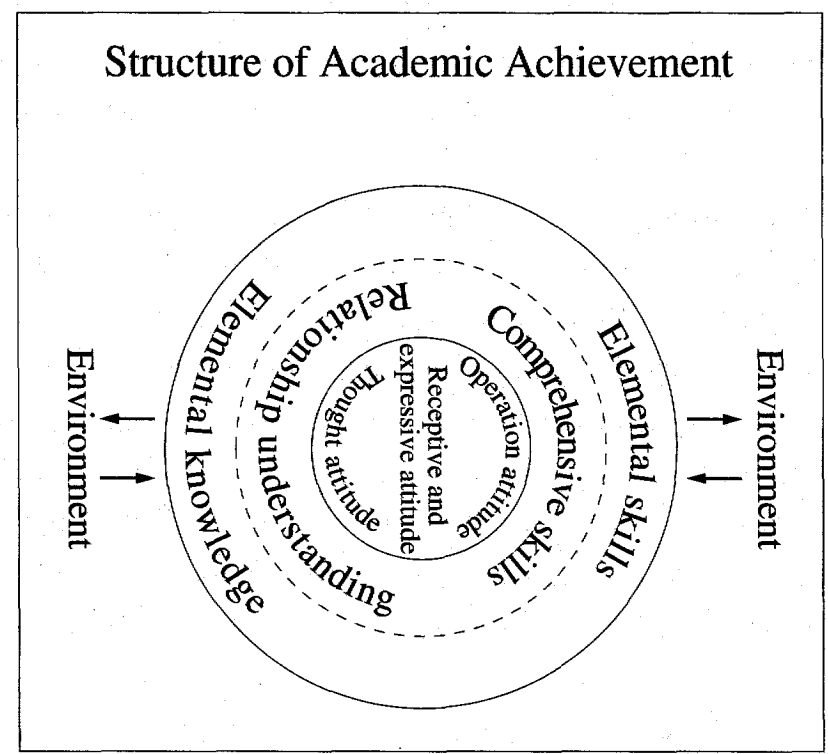

Figure 1 Hirooka's Academic Achievement Model (1964, p.24) 
bility of acquiring knowledge and skills will revert to the children (See for example, Ohtsuki, 1962. See also Ueda 1962a, 1962b, an empiricist who argued against Ohtsuki's arguments).

In contrast, Shuichi Katsuta (1964) took "ability of recognition" as the core of academic achievement. Katsuta (1962) defined academic achievement as "the ability achieved by studying organized educational content whose results can be measured" (p.24). This definition seems to be an excessively narrow definition of academic achievement. However, Katsuta's point was that, by measuring academic achievement, one could "validate the propriety of methods of instruction and the conditions" (p.13), and that educational materials should thus be organized in a rational order.

Toshio Nakauchi (1976) built on Katsuta's ideas and created the academic achievement model shown in Figure 2 (p.74). This figure shows the level at which knowledge, concepts, forms, methods, and themes are acquired and the proficiency level-the level at which these can be fully employed by the learner. This is the basis for measuring academic achievement. Proficiency, as used here, is oriented to "adaptive expertise," which emphasizes flexibility (Matsushita, 1994). Nakauchi's assertion was significant in that it thought attitudes develop on the basis of mastery of educational content. However, Nakauchi's academic achievement model includes affective factors only in the proficiency level. In addition, by separating the mastery level and the proficiency level into two stages, there was a tendency to create a practice in which the proficiency level can only be dealt with in later parts of the instruction process.

Hiroo Inaba (1980), referencing Bloom's Taxonomy of Educational Objectives, believed that cognitive competence and affective disposition developed together. The academic achievement model created by Inaba's group shared a common point with Nakauchi's thought in that it made the development of cognitive competence the core of the unit design (see Tanaka, 2008a, pp.106108). However, this model failed to shed light on the relationship of the development of cognitive competence and affective disposition.

The 17 January 2008 report then emphasized the aspect that desire and attitude support the development of cognitive competence. The report stated that according to the National Academic Achievement and Learning Status Survey, there was a correlation between the children's test scores and children's desire to learn, their learning habits, and their lifestyle (p.14), and it advocated "establishing learning habits, including home learning" (p.27). A theory of the cognitive psychologist Shinichi Ichikawa lies behind this statement. Ichikawa (2004) advocated classes that included developmental learning tasks after the study of textbooks, and the simultaneous development of a home study habit in children.

Essentially, affective elements support cognitive development, and at the same time they develop along with cognitive development. By emphasizing the former, declining academic achievement unavoidably would become the responsibility of the learner. Ichikawa's assertion was that improving the quality of instruction by teachers in the classroom would result in children develop-

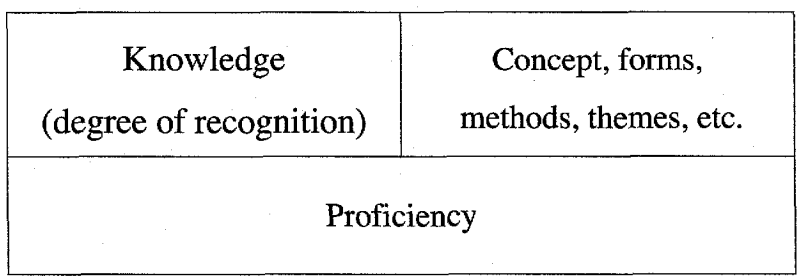

Figure 2 Nakauchi's Academic Achievement Model (1976, p.74) 
ing the habit of studying at home. However, if the report emphasizes the habit of learning at home, it may shift the responsibility for the decline in academic ability to the home.

In contrast, Nakauchi and Inaba were in agreement that educative assessment should be achieved by taking cognitive development as the core of affective development. This opens the way to securing academic achievement for all children. However, their theory left some problems unsolved. One of these was that they could not develop a curriculum design theory that incorporated the cognitive academic achievement that should be secured in each unit and the affective elements.

To overcome this problem, we can again call on the theory of Wiggins and McTighe. In a recently published book they advocate a "Mission-Based Curriculum Framework" (2007, pp.5866). This framework establishes "essential questions" and "enduring understanding" as the goals of each teaching unit, and assigns performance tasks. By repeatedly carrying out similar performance tasks, children acquire overarching "essential questions" and "enduring understanding," that penetrate the whole courses and programs. Moreover, such an aggregation of courses and programs allows students to acquire cross-disciplinary transfer goals and habits of mind throughout the entire school curriculum.

When examined under this framework, the attitude and desire to learn, as emphasized in the 2008 NCS, may need to be divided into two types. First, the attitudes and desire that have conventionally been emphasized for each subject may actually correspond to Nakauchi's "proficiency," or to the "enduring understanding" of Wiggins and McTighe. Such higher-order academic achievement requires the repeated assignment of similar performance tasks, and planning for long-term training and assessment. Conversely, the "desire to learn," "attitude to learning," and "learning habits" valued throughout the curriculum are close to the cross-disciplinary transfer goals and habits of mind posited by Wiggins and McTighe (2007). It is important to distinguish the typical "attitude to learning" with regard to "home study" from academic achievement in each subject, and restrict evaluation to the curriculum.

\section{Conclusion}

The three points examined here have been argued repeatedly for quite some time. Reflecting on this history, first, as we instruct we must remain aware that the 3 Rs are themselves linked to concept formation and recognition methods. Also, in order for students to acquire the ability to inquire during the PFIS, it would be useful to employ performance tasks that have them apply the knowledge and skills in subject classes. Moreover, it would be appropriate to distinguish between attitude and awareness with regard to higher-order academic achievement in each subject, and attitude and awareness with regard to long-term goals that should be fostered throughout the entire curriculum.

The curriculum design methodology offered by Wiggins and McTighe has many implications for constructing the new model for academic achievement that Japan needs. In their "structure of knowledge," they distinguish the important knowledge and skills that should be applied (that is to say, the transferable concepts and complex processes) from factual knowledge and discrete skills. Further, by explicitly describing "enduring understanding," one is able to define an image of exactly how these important knowledge and skills should be applied. Moreover, children acquire the "essential questions" through the process of carrying out performance tasks. The ques- 
tions this process prompts in children will activate inquiries made during the PFIS. Therefore their proposals can be seen as capable of implementing a curriculum that includes the mastery, application, and inquiry that the 2008 revisions to the National Courses of Study seek to achieve. By structuring short-term and long-term goals as suggested in Wiggins and McTighe's "Mission-based Curriculum Framework," we may be able to develop a school curriculum that is effective in fostering positive attitudes toward learning as well as ambition.

\section{References}

Aoki, Seishiro (1949) "New View of Academic Achievement [Gakuryoku no Atarashii Kangaekata]," Seishiro Aoki et al, New Education and the Decline in Academic Achievement [Shin Kyoiku to Gakuryoku Teika], Tokyo: Hara Shobo, pp. 5-20.

Central Council for Education (CCE) [Chuou Kyouiku Shingikai] (2008) "National Courses of Study Reform for Kindergarten, Elementary Schools, Lower and Upper Secondary Schools, and Special-Needs Schools [Youchien, Shougakkou, Chugakkou, Koutougakkou, oyobi Tokubetsushien-gakkou no Gakushushidou-youryou no Kaizen ni tsuite]."

Hirooka, Ryozo (1953) Basic Academic Achievement [Kiso Gakuryoku], Tokyo: Kaneko Shobo.

Hirooka, Ryozo (1964) "What is Academic Achievement and Basic Academic Achievement? [Gakuryoku, Kiso Gakuryoku towa Nanika]," Modern Educational Science-Separate Volume [Bessatsu Gendai Kyouiku Kagaku] 1 (1), Tokyo: Meijitosho Shuppan Corporation, pp. 5-32.

Ichikawa, Shinichi (2004) Fostering the Desire to Learn and Skills [Manabu Iyoku to Skill wo Sodateru], Tokyo: Shogakukan, Inc.

Inaba, Hiroo (1980) "Today's Task of Evaluation of Achievement Study (1) Attainment Targets Issues [Toutatsudo Hyouka Kenkyu no Kon'nichi teki Kadai (1) Toutatsu Mokuhyo wo Meguro Shomondai]," Kyoto Association for the Study of the Criterion-Referenced Evaluation, Editor, Evaluation of Achievement Study Journal [Toutatsudo Hyouka Kenkyu Journal] 1, Tokyo: Chirekisha, pp. 115-138.

Kageyama, Hideo (2002) The Real Way to Improve Academic Achievement [Hontou no Gakuryoku wo Tsukeru Hon], Tokyo: Bungeishunju Ltd.

Kariya, Takehiko (1999) "Academic Achievement in Crisis and Educational Revolution [Gakuryoku no Kiki to Kyoiku Kaikaku]," Central Review [Chuou Kouron] 114 (8) Tokyo: Chuokoron Shinsha, Inc., pp. 36-47.

Kariya, Takehiko (2002) The Illusion of Educational Reform [Kyoiku Kaikaku no Gensou], Tokyo: Chikuma Shobo Publishing Co., Ltd.

Kato, Yukitsugu \& Takaura, Katsuyoshi (2001) A Critique of the Decline of Academic Achievement [Gakuryoku Teika Ron Hihan], Nagoya: Reimei Publishing Co., Ltd.

Katsuta, Shuichi (1962) "What is Academic Achievement? [Gakuryoku towa Nanika]," Education [Kyoiku] 12 (7) Tokyo: Kokudosha Co. Ltd., pp. 10-15, 24-27.

Katsuta, Shuichi (1964) Abilities, Development and Academic Achievement [Nouryoku to Hattatsu to Gakushu], Tokyo: Kokudosha Co. Ltd.

Kishimoto, Hiroshi (1981) Visible Academic Achievement, Invisible Academic Achievement [Mieru Gakuryoku, Mienai Gakuryoku], Tokyo: Ohtsuki Shoten.

Kokubun, Ichitaro (1954) "Protection of Basic Academic Achievement [Kiso Gakuryoku no Bouei]," Searching for Modern Education [Gendai Kyouiku no Tankyu], Tokyo: Mirai-sha Publishers, pp. 59-67 (first published in 1952).

Koyasu, Jun (1999) "Curriculum and Integrated Studies [Kyouiku Katei to Sougou Gakushu]," Toshihiko Hisada, Editor/Author, Theory for Integrated Studies Developed through Collaboration [Kyodou de Tsukuru Sougou Gakushu no Riron], Osaka: Forum A, pp. 41-61.

Matsushita, Kayo (1994) “Three Proficiency Concepts [Mittsu no Shujuku Gainen]," Education [Kyoiku], 44 (2) Tokyo: Kokudosha Co. Ltd., pp. 6-14.

Matsushita, Kayo (2004) "What You Get and Do Not Get from 100-Square Calculations [Hyakumasu Keisan de Naniga Kakutokusare, Naniga Kakutokusarenaika]," Education [Kyoiku] 54 (6) Tokyo: Kokudosha Co. ltd., pp. 20-22.

McTighe, Jay \& Wiggins, Grant (2004) Understanding by Design: Professional Development Workbook, Alexandria: Association for Supervision and Curriculum Development (ASCD).

Ministry of Education, Science and Culture (MESC) [Monbusho](1977) The National Courses of Study for Elementary Schools [Shougakkou Gakushushidou-youryou].

Ministry of Education, Science and Culture (MESC) [Monbusho](1989) The National Courses of Study for Elementary Schools [Shougakkou Gakushushidou-youryou].

Ministry of Education, Science and Culture (MESC) [Monbusho] (1998) The National Courses of Study for Elementary Schools [Shougakkou Gakushushidou-youryou].

Ministry of Education, Culture, Sports, Science and Technology (MEXT) [Monbukagakusho] (2003) The National Cours- 
es of Study for Elementary Schools (Revised in Part) [Shougakkou Gakushushidou-youryou-Ichibu-kaisei].

Ministry of Education, Culture, Sports, Science and Technology (MEXT) [Monbukagakusho] (2005) Instructional Guidelines for Improving Reading Literacy: An Analysis of the Result of the PISA Survey (Reading Literacy) and Directions of Improvement [Dokkai-ryoku Koujou ni kansuru Shidou Shiryo: PISA Chosa (Dokkai-ryoku) no Kekka Bunseki to Kaizen no Houkou].

Ministry of Education, Culture, Sports, Science and Technology (MEXT) [Monbukagakusho] (2008) The National Courses of Study for Elementary Schools [Shougakkou Gakushushidou-youryou].

Nakauchi, Toshio (1976) Revised: Academic Achievement and Evaluation Theory [Zouho: Gakuryoku to Hyouka no Riron], Tokyo: Kokudosha Co. Ltd. (first published in 1967).

Nishioka, Kanae (2005) "The Theory of 'Backward Design' Advocated Wiggins and McTighe [Wiggins to McTighe niyoru 'Gyakumuki-Sekkei'-ron no Igi to Kadai]," The Japanese Society for Curriculum Studies [Nihon Curriculum Gakkai], Editor, The Japanese Journal of Curriculum Studies [Curriculum Kenkyu], 14, pp. 15-29.

Nishioka, Kanae (2007) "Curriculum Development based on the Ideas of Understanding by Design: An Example of its Application to Social Studies in a Junior Secondary School ['Gyakumuki Sekkei'-ron ni Motozuku Curriculum Hensei: Chugakkou Shakaika ni okeru Kaihatsu Jirei]," in the Japanese Society for the Study of Educational Objectives and Evaluation [Kyouiku Mokuhyou Hyouka Gakkai], Editor, The Japanese Journal of Educational Objectives and Evaluation Sttudies [Kyouiku Mokuhyou Hyouka Gakkai Kiyou], 17, pp. 17-24.

Nishioka, Kanae Editor/Author (2008) Guarantee Academic Achievement through "Backward Design" ["Gyakumuki Sekkei" de Tashikana Gakuryoku wo Hosho suru], Tokyo: Meijitosho Shuppan Corporation.

Organisation for Economic Co-operation and Development (OECD) (2003) The PISA 2003 Assessment Framework: Mathematics, Reading, Science and Problem Solving Knowledge and Skills, Paris: OECD publishing.

Ohno, Susumu \& Ueno, Kenji (2001) Academic Achievement Crisis [Gakuryoku ga Abunai], Tokyo: Iwanami Shoten.

Ohtsuki, Takeshi (1962) "About Experience-Attitude-Personalism in Social Studies [Shakaika ni okeru Keiken-TaidoJinkakushugi ni Tsuite]," Education [Kyoiku] 12 (9) Tokyo: Kokudosha Co. Ltd., pp. 8-20.

Okabe, Tsuneharu, Tose, Nobuyuki \& Nishimura, Kazuo Editors (1999) University Students Who Can't Do Fractions [Bunsuu ga Dekinai Daigakusei], Tokyo: Toyo Keizai Inc.

Sato, Manabu (1992) "Proposal: Perspectives That Question Schools-To a Community of Learning [Teigen: Gakkou wo Tou Perspective-Manabi no Kyodoutai he]," Yutaka Saeki, Toshiyuki Shiomi, Manabu Sato Editors, Aiming to Revive Schools, vol. 1-Questioning the School [Gakkou no Saisei wo Mezashite 1 - Gakkou wo Tou], Tokyo: Tokyo University Publishers, pp. 197-224.

Sato, Manabu (1999) Designing Educational Reform [Kyouiku Kaikaku wo Design Suru], Tokyo: Iwanami Shoten.

Shibata, Yoshimatsu (2003) Why the 3Rs are Basic Academic Achievement ["Dokushosan" wa Naze Kiso Gakuryoku Ka], Tokyo: Meiji Tosho Shuppan Co., Ltd.

Shiomi, Toshiyuki (2001) "Beyond 'Academic Abilities' ['Gakuryoku' wo Koeru]," Naoki Iwakawa, Toshiyuki Shiomi Authors/Editors, Questioning "Academic Ability" [Gakuryoku wo Tou], Tokyo: Soudo Bunka.

Shiromaru, Fumio (1959) "Basic Academic Achievement Theory [Kiso Gakuryoku ron]," Modern Japanese Educational Theory [Gendai Nihon Kyouiku-ron], Tokyo: Shinhyoron Co., Ltd.

Tanaka, Koji (1996) Introductory for Academic Achievement Assessment Theory [Gakuryoku Hyouka-ron Nyumon], Kyoto: Hosei Shuppan.

Tanaka, Koji (1999) "Why Integrated Studies Now? [Ima, Naze Sougou Gakushu Nanoka?]," Koji Tanaka \& Kanae Nishioka, Integrated Studies and Portfolio Assessment: An Introduction [Sougou Gakushu to Portfolio Hyoukahou: Nyumon hen], Tokyo: Nippon Hyojun Co., Ltd. pp. 7-26.

Tanaka, Koji (2008a) Educational Assessment [Kyouiku Hyouka], Tokyo: Iwanami Shoten.

Tanaka, Koji (2008b) "Academic Achievement Survey and Educational Assessment Research," Japanese Educational Research Association, 75(2), pp. 146-156.

Ueda, Kaoru (1962a) "What is Knowledge Mistrust: Criticizing Ohtsuki's Article (1) [Nani wo Chishiki Fushin to Iuka: Ohtsuki Ronbun Hihan (jou)]," Education [Kyoiku], 12 (11) Tokyo: Kokudosha Co. Ltd., pp. 75-80.

Ueda, Kaoru (1962b) "Education and Science: Criticizing Ohtsuki's Article (2) [Kyoiku to Kagaku: Ohtsuki Ronbun Hihan (ge)]," Education [Kyoiku], 12 (12) Tokyo: Kokudosha Co. Ltd. pp. 79-85.

Wada, Hideki (2002) How to Protect Children from "Relaxed Education" ["Yutori Kyouiku" kara Kodomo wo Dou Mamoruka], Tokyo: Kodansha Ltd.

Wiggins, Grant \& McTighe, Jay (1998) Understanding by Design, Alexandria: Association for Supervision and Curriculum Development (ASCD).

Wiggins, Grant \& McTighe, Jay (2005) Understanding by Design, Expanded $2^{\text {nd }}$ Ed.; Alexandria: Association for Supervision and Curriculum Development (ASCD).

Wiggins, Grant \& McTighe, Jay (2007) Schooling by Design, Alexandria: Association for Supervision and Curriculum Development (ASCD). 